University of Nebraska - Lincoln

DigitalCommons@University of Nebraska - Lincoln

Faculty Publications, Department of Psychology

Psychology, Department of

6-2008

\title{
Supracutaneous vibrotactile perception threshold at various non- glabrous body loci
}

\author{
Miriam Bikah \\ University of Nebraska-Lincoln \\ M. Susan Hallbeck \\ University of Nebraska-Lincoln, hallbeck@unl.edu \\ John H. Flowers \\ University of Nebraska-Lincoln, jflowers1@unl.edu
}

Follow this and additional works at: https://digitalcommons.unl.edu/psychfacpub

Part of the Psychiatry and Psychology Commons

Bikah, Miriam; Hallbeck, M. Susan; and Flowers, John H., "Supracutaneous vibrotactile perception threshold at various non-glabrous body loci" (2008). Faculty Publications, Department of Psychology. 433. https://digitalcommons.unl.edu/psychfacpub/433

This Article is brought to you for free and open access by the Psychology, Department of at DigitalCommons@University of Nebraska - Lincoln. It has been accepted for inclusion in Faculty Publications, Department of Psychology by an authorized administrator of DigitalCommons@University of Nebraska - Lincoln. 


\title{
Supracutaneous vibrotactile perception threshold at various non-glabrous body loci
}

\author{
Myriam Bikah, ${ }^{1}$ M. Susan Hallbeck, ${ }^{1}$ and John H. Flowers ${ }^{2}$ \\ 1. Department of Industrial Engineering, 175 Nebraska Hall, \\ University of Nebraska-Lincoln, Lincoln, NE 68588, USA \\ 2. Department of Psychology, 238 Burnett Hall, \\ University of Nebraska-Lincoln, Lincoln, NE 68588, USA \\ Corresponding author - M. S. Hallbeck, email hallbeck@unl.edu
}

\begin{abstract}
Researchers at the University of Nebraska-Lincoln are currently designing a wearable/portable neutron detector. As an alerting mechanism, the device will transmit vibration to the wearer's skin in the presence of hazardous levels of neutron radiation. The present study was designed to help in the ergonomically correct body placement of the neutron detection device while providing numerical values for vibratory thresholds at the surface of various non-glabrous body loci. The aim of the study was to investigate the underlying effects of locus stimulated, amount of subcutaneous fat around a specific body site and gender on low frequency vibration thresholds. Thirty-six participants, who were categorized by both dichotomous body fat group (high or low) and gender, were tested at 24 loci orthogonally located around six body sites: head; neck; upper arm; wrist; waist; ankle. The results indicated that frequency threshold depends significantly on the locus stimulated $(p=0.001)$. The nape of the neck had the greatest sensitivity to low frequency stimulations, while the loci around the waist were least sensitive. Also, body fat significantly affected ability to perceive vibratory stimuli ( $p=$ 0.048 ), with the mean frequency threshold of the low body fat group lower than that of the high body fat group. There was no statistical difference in thresholds with gender.
\end{abstract}

Keywords: vibrotactile perception threshold; vibrotactile device; cutaneous perception

\section{Introduction}

Exposure to neutron radiation can cause severe damage to humans' internal organs, including blood-forming marrow. Accidental or malevolent release of neutron radiation can result in serious human and economic losses. Unfortunately, the human senses cannot detect neutrons; a special instrument, a neutron detector, must be utilized for this purpose. In the current war on terror, the need for radiation detectors is well established.

Ergonomic research is currently undertaken as part of the design of a wearable vibrotactile neutron detector. In the presence of hazardous levels of neutron radiation, the detector will alert first responders, HAZMAT teams or Transportation Safety Administration personnel. The design of such a device must balance the issues of power consumption (battery life and weight) with the need to produce alarm signals that can be accurately and reliably perceived by the users. This may mean that amplitude levels and 
perhaps stimulation frequencies for this device could be much lower than those found in current tactile displays. Therefore, a study was conducted to evaluate minimal permissible values for the frequency and amplitude of the vibratory signals emitted by the device. In theory, the most sensitive body locus would require less battery power to be stimulated as opposed to least sensitive loci. For the purpose of this study, "vibration" is defined as any stimulation perceptible by touch.

\subsection{The human skin}

When a vibratory stimulus is presented to the skin, a mechanical wave propagates on and in the skin and the tissues innervated become displaced from their resting state (Cholewiak et al. 2001). The skin contains a number of different sensory receptors, which have the function of transforming tactile stimuli into electrical signals that can be processed by the nervous system. The specialized mechanoreceptors of the skin react differently depending on the specific locus stimulated and the amplitude and frequency of the vibration pulse. The epidermis and dermis of the skin house four types of mechanoreceptors that are unique in their receptive field sizes and rate at which they adapt to mechanical stimuli (Goldstein 2002). The Merkel receptors are located near the border between the dermis and the epidermis; they respond to frequencies ranging from 0.3 to $3 \mathrm{~Hz}$. The Meissner corpuscles are located just beneath the epidermis and can detect frequencies in the range of 3 to $40 \mathrm{~Hz}$. Ruffini cylinders and Pacinian corpuscles are found in the deeper tissues of the skin; they are responsible for the perception of stimuli whose frequencies vary between 15 and $400 \mathrm{~Hz}$ and between 10 and $500 \mathrm{~Hz}$ respectively (Goldstein 2002).

\subsection{Physiological variables affecting cutaneous sensitivity}

Predicting and measuring cutaneous sensitivity to tactile stimuli presents an interesting challenge for neurologists, psychologists and designers. In addition to the different frequency sensitivities of the different types of tactile receptors, and differences in densities of the receptor types among regions of the body, several additional factors affect sensitivity to tactile stimulus. These include soft tissue thickness, skin temperature, gender, age, duration of the stimulation, body fat, whether the stimulation is applied to glabrous or non-glabrous skin and the methodology and apparatus used in a study.

Verrillo (1979) conducted an evaluation of vibrotactile thresholds at the thenar eminence; he noted a loss of sensitivity for high frequencies with advancing age. Stuart et al. (2003) also investigated the effects of ageing on vibration perception thresholds. They compared thresholds of a group of young adults (17-27 years old) to a group of elderly adults (55-90 years old) at four skin sites (palmar surface of the tip of the middle finger, volar surface of the forearm, lateral aspect of the shoulder, cheek, just caudal to the zygoma). Their study concluded that vibrotactile acuity deteriorated with advancing age. The study also revealed that, overall, the fingertips were the most sensitive sites for vibrotactile detection. Furthermore, unlike the other body sites tested, sensation at the fingertips did not decline significantly with age. The authors attributed the latter finding to the high receptor density at the fingertips or the major role of vibrotactile sensitivity at this area or a combination of the two factors (Stuart et al. 2003).

In addition, Morioka and Griffin (2005) conducted three experiments aimed at establishing the effect of contact area, location and surround on the perception of hand-transmitted vibration. They found that when no surround was present, the thresholds of fibers related to the Meissner's corpuscles increased at frequencies less than $31.5 \mathrm{~Hz}$, while the 
threshold of fibers related to the Pacinian corpuscles decreased at frequencies greater than about $63 \mathrm{~Hz}$. Harazin et al. (2005) conducted a comparison study of vibrotactile perception threshold (VPT) values using two different assessment modes: one was designed according to the requirements of the ISO 13091-1 standard (ISO method) (International Organization for Standardization 2003) and, at the time of their study, the other mode had only been used in Poland (Polish method). The VPT values were measured at the fingertips of the index, middle and ring fingers of the participants' two hands. Their study revealed that the VPT values obtained using the ISO method were significantly higher than those obtained via the Polish method. Therefore, threshold is also a function of the methodology and apparatus used in a study.

Cohen and Lindley (1938) investigated the effects of pressure variations on surfaces of different resiliency. Their results showed an inverse relationship between threshold values and thickness of overlying soft tissue: threshold values were higher on the thigh than on the patella and tibia, and the values obtained on the tibia were lower than those collected on the patella. Furthermore, the tactile sense is more acute on glabrous palmar skin than it is on the hairy skin (Boff et al. 1986). An earlier work by Weber (1834) found that perception of cutaneous stimulations depends on the body locus examined. Weber (1834) measured the two-point threshold across the surface of the body and reported that it varied greatly. According to Goodfellow (1938), the ability to perceive tactile stimuli also varies between individuals. Moreover, Goff et al. (1965) reported that, in general, females were more sensitive to vibration than males.

\subsection{Subcutaneous fat distribution in humans}

Adipose tissue, commonly called body fat, is a major source of energy and insulation for the body. Every human being carries some amount of body fat, although in varying quantity and thickness. Some factors influencing the distribution of fat within adipose tissue comprise genetic inheritance, gender, nutrition, physical activity and hormones (Renold and Cahill 1965). According to Renold and Cahill (1965), the following areas of the body are predisposed to fat accumulation (although the list is not exhaustive and only contains the body loci tested in the present experiment): the nape of the neck, behind the first three cervical vertebrae; the back of the upper arm along the triceps muscle; the abdomen, below the umbilicus. The theory states that the more body fat accumulates in a body locus, the less sensitive it is to vibratory stimulations. Consequently, among the six body sites tested, the neck, upper arm and waist were expected to have higher thresholds, on average, than the head, wrist and ankle.

Furthermore, the density of adipocytes at various loci depends on whether a person has a gynoid or android body constitution. Gynoid adipose tissue tends to accumulate mostly over the lower half of the body: hypogastrium, pelvis, anterior aspect of the thigh, internal surface of the knee; android adipose tissue develops mostly over the upper half of the body: nape of the neck, deltoid area, epigastrium (Renold and Cahill 1965). Most males follow the android constitution, while the gynoid constitution is that of the majority of females (Renold and Cahill 1965), which can explain the relationship between body fat distribution patterns and gender.

\subsection{Study objective}

While physiological variables affecting cutaneous sensitivity have been explored extensively, there is no data found in the literature dealing with low power, low fre- 
quency, square wave stimulations, even though they are practical for the design of wearable and portable neutron detection devices. One of the hypotheses investigated in this study was that subcutaneous fat interferes with humans' ability to perceive supracutaneous vibrotactile stimulations. Therefore, human sensitivity to vibration will depend on the body site stimulated, since fat is distributed unevenly over the body. Further, this allows the extrapolation that people with low body fat have lower vibratory thresholds than those with significantly higher body fat. A damping-type effect may explain why body fat would act as a buffer when vibration is applied to the skin. Moreover, because of their gynoid body constitution, females were expected to have lower thresholds than males in areas above the abdomen, while males were expected to be more sensitive in areas around the ankle.

\section{Methodology}

The study was approved by the Institutional Review Board of the University of Nebraska- Lincoln and all participants signed a written informed consent prior to data collection in a campus laboratory. No measures were made of skin temperature but the conditions of the room were kept relatively constant $\left(\sim 74^{\circ} \mathrm{F}\right)$ in order to minimize variability of skin temperature.

\subsection{Participants}

A total of 36 individuals (18 males and 18 females) were recruited from the student population at the University of Nebraska. The participant group had a minimum age of 19 years; males had a mean age of 28 (SD 10.5) years and females averaged 26 (SD 10.7) years of age. All the participants were in good general health, reporting no history of upper or lower limb nerve lesions, peripheral vascular disease or diabetes mellitus.

\subsection{Body fat measurements}

Participants were categorized into three groups according to their subcutaneous fat percentage as low, medium or high body fat content, using the skinfold procedure. A Lange skinfold calliper (Beta Technology Inc., Cambridge, MA, USA) was used to perform body fat measurements. This procedure is widely used by fitness and medical professionals for measurement of subcutaneous tissue. The process described by the American College of Sports Medicine (Johnson 2000) was followed to perform the skinfold test. The principal investigator was trained to administer this test accurately.

Men were tested at the chest, abdomen and thigh. The following two formulae were used to calculate men's body fat percentage (BFP):

$$
\mathrm{BFP}=495 \div \text { Body Density }-450 \quad \text { (Siri 1956) }
$$

where men's body density $=1.10938-0.0008267 \times$ (sum of 3 skinfolds $)+0.0000016 \times$ $(\text { sum of } 3 \text { skinfold })^{2}-0.0002574 \times($ Age $)($ Johnson 2000$)$.

Women were tested at the triceps, suprailiac and thigh. The following formulae were used to calculate their BFP:

$$
\mathrm{BFP}=495 \div \text { Body Density }-450 \quad \text { (Siri 1956) }
$$


where women's body density $=1.099421-0.0009929 \times$ (sum of 3 skinfolds) $) 0.0000023 \times$ (sum of 3 skinfold) $)^{2}-0.0001392 \times($ Age) (Johnson 2000)

Table 1 shows the participant classification scheme relative to body fat percent for both males and females. This table was extrapolated from data provided by the American College of Sports Medicine (Johnson 2000), which published BFPs for 50th percentile men and women. The BFPs found in Table 1 were selected well below (for the low BFP group) and above (for the high BFP group) the average reported by Johnson (2000), to make a clear dichotomy between the two groups.

To determine if they belonged to the low, medium or high body fat group, participants' BFPs were compared to the numerical values found in Table 1. Participants whose BFP fell in the "medium" category were excluded from the study. The 36 participants were stratified into dichotomous body fat groups as follows: nine males with low BFP ( $\mu$ $=11.2$, SD 3.7); nine males with high BFP $(\mu=27.5$, SD 5.0); nine females with low BFP $(\mu$ = 20.9, SD 1.2); nine females with high $\operatorname{BFP}(\mu=35.6$, SD 7.3).

\subsection{Apparatus}

Square wave vibration was delivered via miniature vibrotactile wired Mylar-cone speakers (MCM Electronics Centreville, OH, USA, Model \# SR00186) (4 cm diameter; impedance: $16 \mathrm{ohm}$; frequency: $300 \mathrm{~Hz}$; power rated (max.): 0.001 (0.002) W resonant) placed directly against the skin. The speakers were positioned at four orthogonal loci for each body site tested. An assessment of commercial products revealed that the selected speakers could generate low frequency vibrations reliably. The selection of this equipment was based on other studies that have used similar loudspeakers to relay vibratory stimulations successfully (Plant et al. 1994, Dennerlein et al. 1997). A pilot study showed that square wave signals were most stable for the type of instruments used in the study. The speakers were held in place by a stretch elastic band $(3.6 \mathrm{~cm}$ wide). Square wave voltage was generated by a BK Precision 4003A $4 \mathrm{MHz}$ function generator (B\&K Precision, Yorba Linda CA, USA) and the signal was passed to a CARVER PM600 magnetic field power amplifier (Carver PM600, Portland, OR, USA). The speakers were directly connected to the power amplifier, from which the investigator was able to set the amplitude output. Music earphones were provided to the participants to mask the tapping noise emitted by the vibrating speakers. Participants listened to classical music for the duration of the experiment; each participant receiving the same playlist at the same volume. All participants were standing throughout the experiment. Vibratory signals were introduced consecutively at each of the 24 body loci described below.

\subsection{Experimental procedures}

\subsubsection{Vibration threshold test}

Table 2 gives a description of the 24 body loci tested. Figures 1, 2 and 3 are illustrations of the body loci stimulated at the head, wrist and waist, respectively. The loci investigated at the neck, upper arm and ankle are not illustrated, as the description given below provides a clearer representation of their location.

According to Craig and Sherrick (1982), vibrotactile perception deteriorates above 28 $\mathrm{dB}$. Prior to the actual investigation, the authors conducted a pilot study to evaluate this conjecture and determine the "just noticeable value" for intensity. The four pilot study participants were able to feel amplitudes as low as $20 \mathrm{~dB}$. Therefore, throughout the pres- 


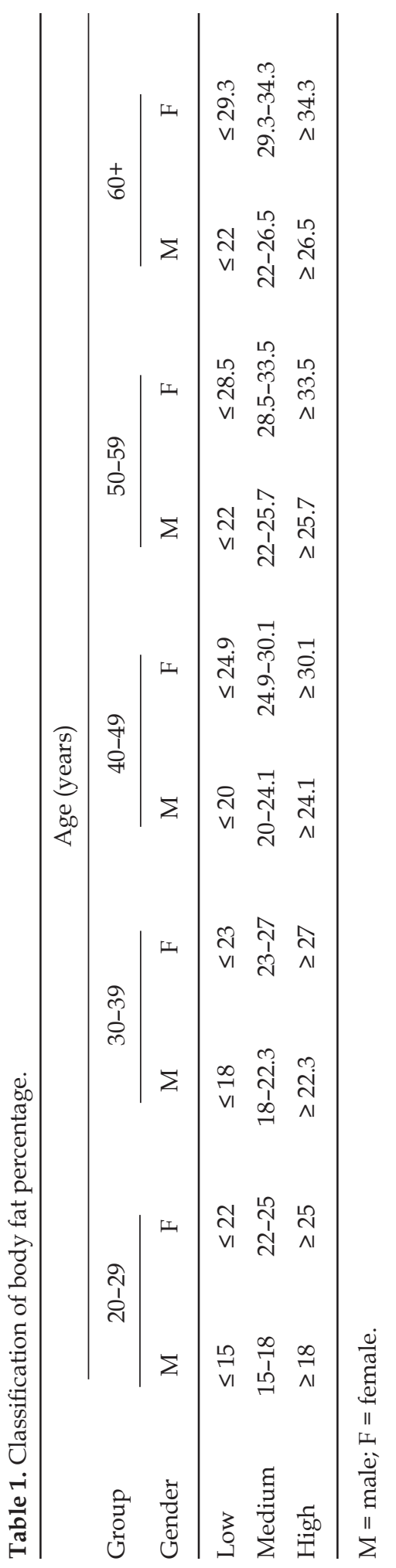



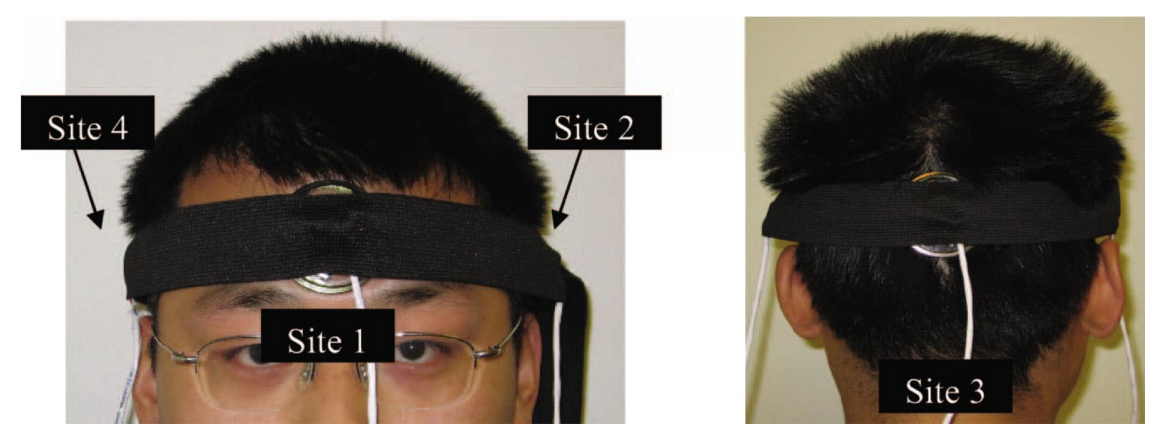

Figure 1. Loci where the four Mylar cone speakers were placed at the head.

ent study, the amplitude was kept constant at $20 \mathrm{~dB}$ and the frequency was varied. As stated previously, the Mylar-cone speakers were directly connected to the power amplifier, from which the investigator was able to set the amplitude output to $20 \mathrm{~dB}$.

The investigation was conducted similar to a hearing-type test. The psychophysical method of limits was used to measure the frequency at absolute threshold. At each lo-

Table 2. Description of the 24 body loci investigated.

\begin{tabular}{|c|c|c|}
\hline Site & Description & \\
\hline \multirow[t]{4}{*}{ Head } & Locus 1: & $\begin{array}{l}\text { Anterior surface of the skull, on the frontal bone, immediately } \\
\text { superior to the glabella }\end{array}$ \\
\hline & Locus 2: & $\begin{array}{l}\text { Left lateral surface of the skull, above the left ear, on the } \\
\text { temporal and parietal bones }\end{array}$ \\
\hline & Locus 3: & Posterior surface of the skull, on the occipital bone \\
\hline & Locus 4: & $\begin{array}{l}\text { Right lateral surface of the skull, above the right ear, on the } \\
\text { temporal and parietal bones }\end{array}$ \\
\hline \multirow[t]{4}{*}{ Neck } & Locus 5: & Anterior surface, on the thyroid and cricoid cartilage \\
\hline & Locus 6: & $\begin{array}{l}\text { Left side of the neck, inferior to the left ear, on the } \\
\text { sternocleidomastoid muscle }\end{array}$ \\
\hline & Locus 7: & Nape of the neck, along the cervical curvature \\
\hline & Locus 8: & $\begin{array}{l}\text { Right side of the neck, inferior to the right ear, on the } \\
\text { sternocleidomastoid muscle }\end{array}$ \\
\hline \multirow[t]{4}{*}{ Upper arm (right) } & Locus 9: & Superior to the brachioradialis muscle \\
\hline & Locus 10: & On the biceps muscle \\
\hline & Locus 11: & Along the coracobrachialis muscle \\
\hline & Locus 12: & Back of the upper arm, along the triceps muscle \\
\hline \multirow[t]{4}{*}{ Wrist (right) } & Locus 13: & On the brachioradialis tendon \\
\hline & Locus 14: & Anterior surface, along the palmar carpal ligament \\
\hline & Locus 15: & Superior to the pisiform, on the flexor carpi ulnaris tendon \\
\hline & Locus 16: & Posterior surface, on the extensor retinaculum \\
\hline \multirow[t]{4}{*}{ Waist } & Locus 17: & Abdominal region, inferior to the umbilicus \\
\hline & Locus 18: & On the left lateral region \\
\hline & Locus 19: & $\begin{array}{l}\text { Dorsal region, along the spinal region, superior to the fifth } \\
\text { lumbar vertebra }\end{array}$ \\
\hline & Locus 20: & On the right lateral region \\
\hline \multirow[t]{4}{*}{ Ankle (right) } & Locus 21: & On the superior extensor retinaculum \\
\hline & Locus 22: & Superior to the medial malleolus \\
\hline & Locus 23: & Superior to the subcutaneous calcaneal bursa \\
\hline & Locus 24: & Superior to the lateral malleolus \\
\hline
\end{tabular}



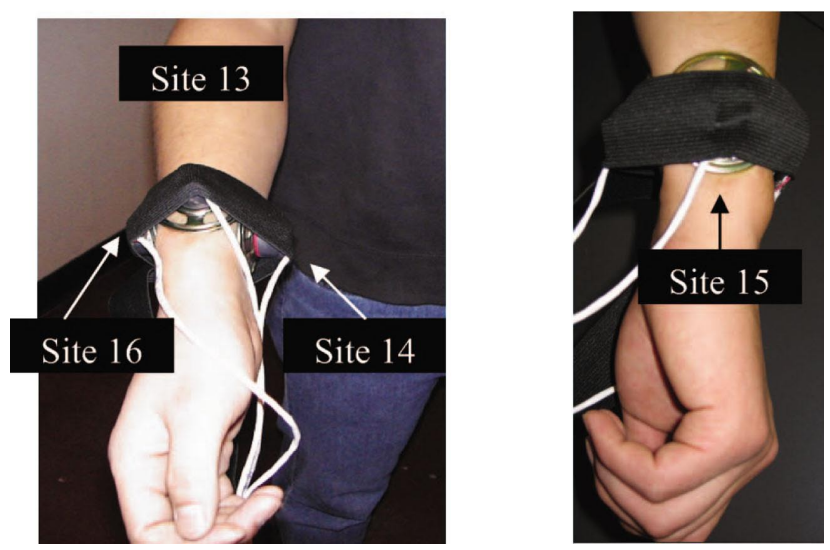

Figure 2. Loci where the four Mylar cone speakers were placed at the wrist.
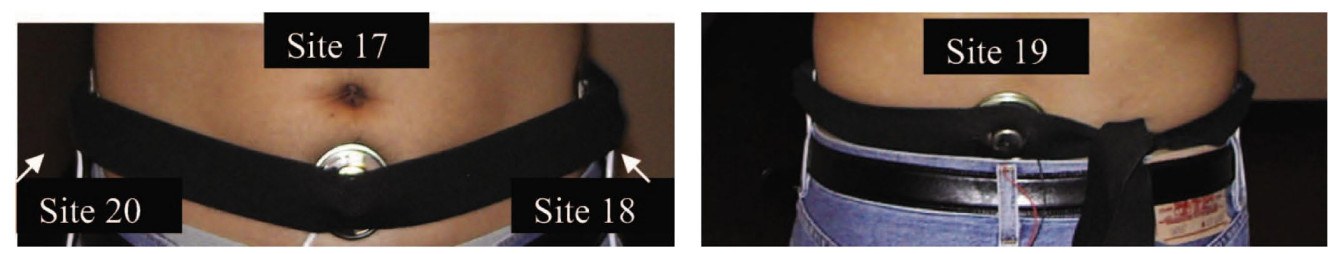

Figure 3. Loci where the four Mylar cone speakers were placed at the waist.

cus, participants initially experienced a frequency of vibration below the threshold of detection $(=0 \mathrm{~Hz}$, generator turned off). The frequency was then gradually increased in 0.1 $\mathrm{Hz}$ increments until the stimulation was perceived (ascending mode); the signal was constantly on and the investigator paused for $5 \mathrm{~s}$ at each increment increase. Subsequently, the ascending frequency threshold was entered by the investigator into an Excel spreadsheet (Microsoft Corporation, Redmond, WA, USA). The generator was turned back off. Then, participants experienced a vibratory frequency of $5 \mathrm{~Hz}$ (well above the threshold of detection). The frequency was then gradually decreased in increments of $0.1 \mathrm{~Hz}$ until participants could no longer feel the stimulus (descending mode); the signal was also constantly on and the investigator paused for $5 \mathrm{~s}$ at each increment increase. Participants orally indicated by a "yes" when they could feel the vibration and with a "no" they indicated that the signal could no longer be felt. Participants were given a visual signal of when to say "yes" or "no" within each 5-s interval. On ascending trials, the threshold value was recorded as the level at which the participant provided the first "yes" response, while on descending trials the threshold value was recorded as the level at which the first "no" response was given.

\subsection{Experimental design}

Threshold was calculated by averaging the frequency obtained on the ascending and descending trials. Descriptive statistics (mean and standard deviation) were used to summarize the vibratory thresholds across the six body sites tested and to identify the general trends in supracutaneous vibrotactile sensitivity (Figure 4). 


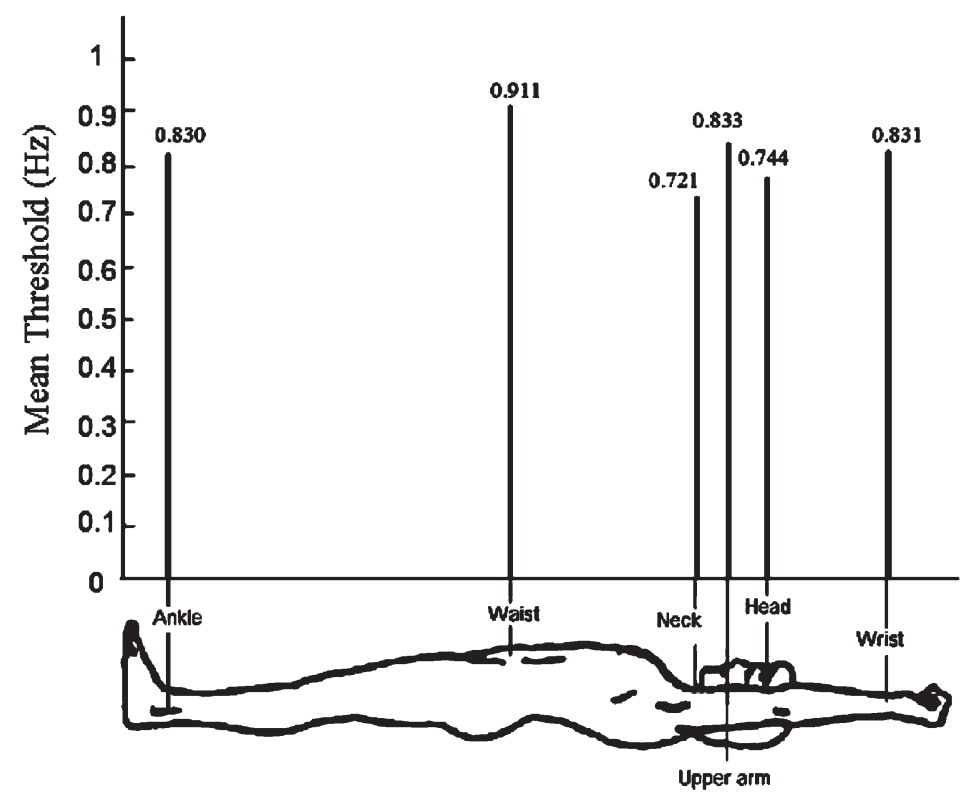

Figure 4. Absolute threshold for vibrotactile perception at the six body sites tested.

\subsubsection{Independent variables}

2.5.1.1. Comparison of vibratory thresholds at various body loci. An evaluation of vibrotactile frequency threshold as a function of body locus stimulated was undertaken. For this analysis the independent variable was the locus of the stimulation, with a total of 24 body loci located at the head, neck, upper arm, wrist, waist and ankle.

2.5.1.2. Effect of subcutaneous fat on perception threshold. An investigation of the effect of subcutaneous fat on absolute frequency threshold was performed. The body fat group (low or high) of all participants and the site stimulated (six levels: head; neck; upper arm; wrist; waist; ankle) were selected as independent variables. At each site, the threshold was calculated by averaging the frequency of all loci for that site (for example, the threshold at the head was found by averaging that of loci 1 to 4 ).

2.5.1.3. Effect of gender. A comparison of males' and females' vibratory frequency thresholds was performed. The independent variables were the dichotomous gender group and the site stimulated (six levels: head; neck; upper arm; wrist; waist; ankle). Again, the threshold at each site was calculated by averaging the frequencies of all the loci at that site.

\subsubsection{Dependent variables}

2.5.2.1. Effect of body locus on vibratory frequency threshold. To analyze the effect of locus stimulated on vibrotactile frequency threshold, the dependent variables included the frequency data for the absolute thresholds at the 24 loci stimulated.

2.5.2.2. Frequency threshold as a function of body fat. To analyze the effect of body fat on perception threshold, the dependent variables included the frequency thresholds at the six body sites tested. 
2.5.2.3. Frequency threshold as function of gender. The effect of gender was also tested using the frequency threshold data at the six body sites as dependent variables.

\subsubsection{Statistical analyses}

2.5.3.1. Vibratory threshold as a function of body loci. To examine the effect of varying body loci on frequency threshold the dependent variables were statistically analyzed using the Friedman test. This test is commonly used to assess if $k$ repeated measures come from populations with the same median (Siegel and Castellan 1988). The Wilcoxon post hoc analysis with a Bonferroni correction for increased type I error was utilized when a significant difference was found by the Friedman test, but only body loci at which 95\% CI did not overlap were compared. The number of comparisons was restricted to avoid making $\left(\begin{array}{c}24 \\ 2\end{array}\right)=276$ comparisons and therefore causing a type II error increase.

2.5.3.2. Effect of body fat. To analyze the effect of body fat on VPTs, a two-way ANOVA, formatted A $\times$ B with repeated measures on variable B, was utilized. Variable A was defined as body fat group (low or high); variable B represented the site stimulated (head, neck, upper arm, wrist, waist and ankle).

2.5.3.3. Effect of gender on frequency sensitivity. To analyze the effect of gender on detection threshold, a two-way ANOVA, formatted A $\times$ B with repeated measures on variable B, was also utilized. Variable A was defined as gender; variable B represented the site stimulated (head, neck, upper arm, wrist, waist and ankle).

\section{Results}

\subsection{Mean threshold at the six stimulation sites}

Figure 4 schematically shows the mean frequency threshold at the head, neck, upper arm, wrist, waist and ankle. The waist $(\mu=0.911 \mathrm{~Hz}$, SD $0.393 \mathrm{~Hz})$ was the least sensitive to low vibratory frequencies; the neck $(\mu=0.721 \mathrm{~Hz}$, SD $0.233 \mathrm{~Hz})$ was the most effective in detecting vibratory signals. Interestingly, every location tested had an absolute threshold less than $1 \mathrm{~Hz}$.

\subsection{Comparison of vibrotactile thresholds at various body loci}

The results of the Friedman test indicated that there was a significant difference in the median threshold frequencies $(p=0.001)$ across the 24 body loci. Figure 5 shows the margin of error bounds of the 95\% CI. Locus 7 (nape of the neck) was one of the most sensitive to low frequency vibrations and locus 20 (right lateral region of the waist) was one of the least sensitive.

Wilcoxon post hoc analyses with adjustment of the two-tailed level to $0.007(0.05 / 7)$ indicated that locus 7 (nape of neck, mean difference $(\mathrm{md})=0.60 \mathrm{~Hz}$ ) had a significantly lower threshold of detection than every locus of the waist (locus 17: $\mathrm{md}=0.84 \mathrm{~Hz}, p<$ 0.001; locus 18: $\mathrm{md}=0.76 \mathrm{~Hz}, p<0.001$; locus 19: $\mathrm{md}=0.85 \mathrm{~Hz}, p<0.001$; locus 20: $\mathrm{md}=$ $0.85 \mathrm{~Hz}, p<0.001$ ). Locus 7 also had a significantly lower threshold than locus 23 of the ankle (below the right calf, $\mathrm{md}=0.85 \mathrm{~Hz}, p<0.001$ ) and locus 13 ( $\mathrm{md}=0.81, p<0.001$ ) located on the brachioradialis tendon of the right wrist. Locus 2 (above the left ear, md = $0.71 \mathrm{~Hz}$ ) was also statistically more sensitive to low frequency vibrations than locus 20 (right lateral region of the waist, $\mathrm{md}=0.85 \mathrm{~Hz}, p<0.001$ ). 


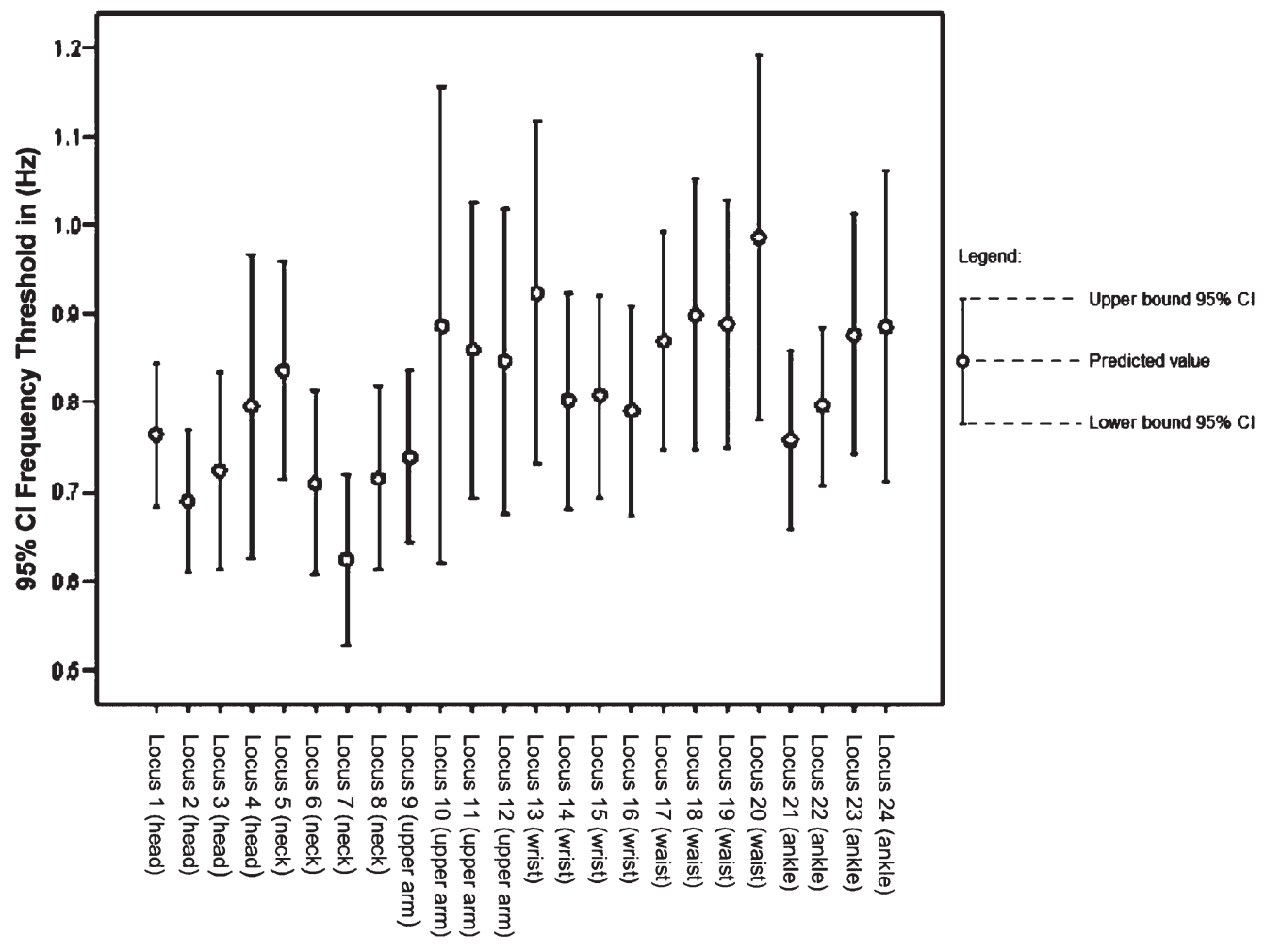

Body Loci

Figure 5. CI for mean frequency threshold at 24 body loci.

\subsection{Absolute threshold as a function of subcutaneous fat}

The ANOVA revealed a significant effect of body fat $(p=0.048)$. As indicated in Figure 6, people with high body fat were less sensitive to low frequency vibrations than people with low body fat at each of the 24 body sites tested. The two body fat groups differ the most at site 20 ( $\mathrm{md}=0.375 \mathrm{~Hz}$ ), located on the right lateral region of the waist; the groups differ the least at site $23(\mathrm{md}=0.043 \mathrm{~Hz}$ ), located on the right ankle, below the calf.

\subsection{Effect of gender}

The ANOVA showed no significant differences in detection thresholds for males and females at the six stimulation sites $(p=0.159)$. Figure 7 shows the comparison between males and females at the six sites.

\section{Discussion}

A major design concern for wearable vibrotactile instruments is to develop devices that can be used in the field for long periods of time. This study showed that low power square wave stimulations less than $2 \mathrm{~Hz}$ can definitely be detected by the human skin and that gender plays virtually no role for the detection of such stimuli. However, body fat was shown to hinder the ability to perceive vibration. Therefore, the effect of subcutane- 


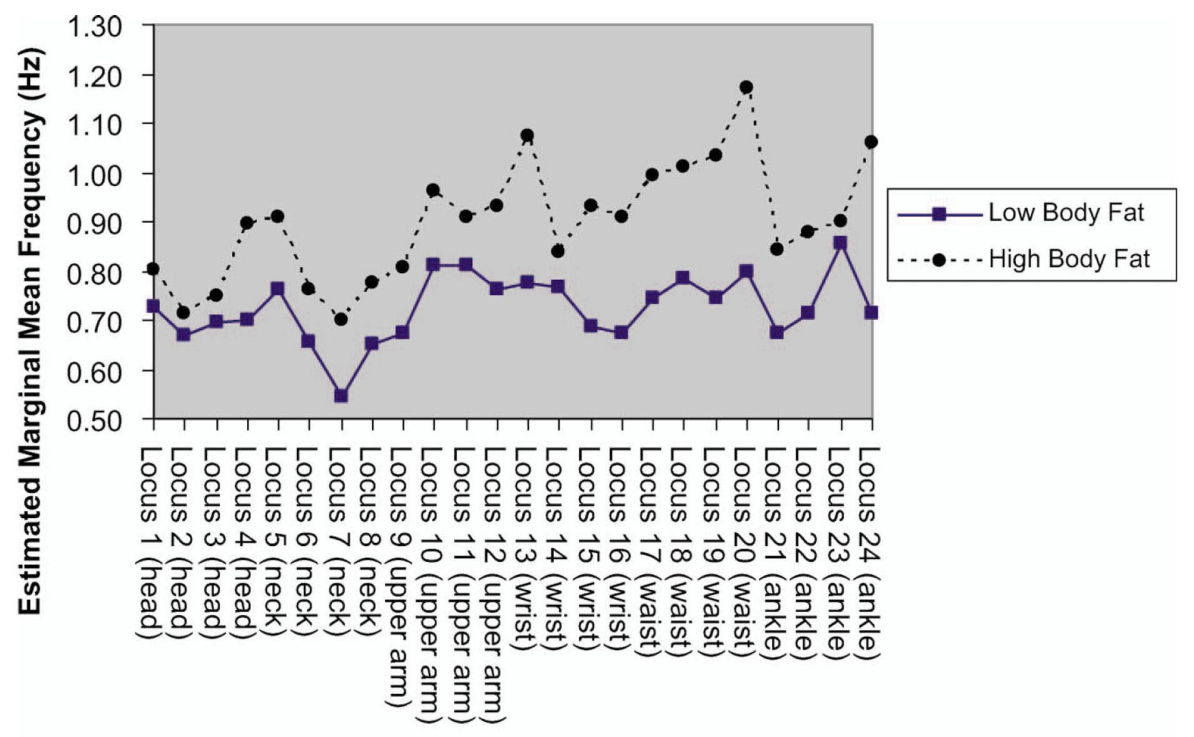

Body Loci

Figure 6. Estimated marginal means of frequency thresholds at 24 body loci for the two body fat groups.

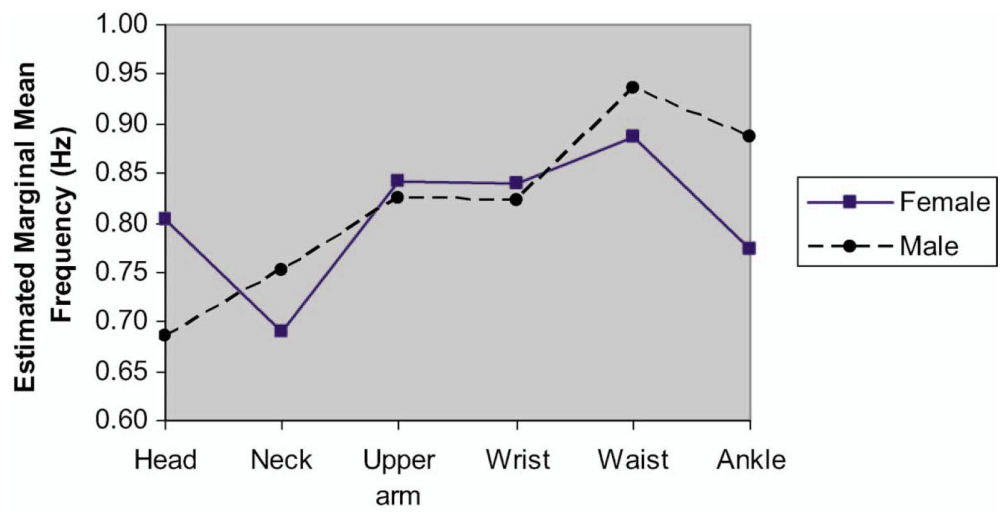

Body Sites

Figure 7. Estimated marginal means of frequency thresholds at the six body sites for males and females

ous fat must be carefully considered prior to the final selection of the amplitude and frequency for the alerting mechanism of a vibrotactile device.

As hypothesized, perception of low frequency vibrations is dependent on both body fat and locus stimulated. Among the 24 body loci investigated, the nape of the neck was one of the most sensitive, while areas located around the waist had higher frequency thresholds. These results are comparable to investigations conducted by Weber (1834), which concluded that different parts of the body differed in tactile acuity. In addition, Weber (1834) noted greater touch-sense sensitivity in the region of the neck as compared 
to other parts of the trunk. This is partly due to the fact that body loci of acute sensitivity enclose more nerve endings whose function is to (indirectly) activate sensory receptors. The low density of skin receptors (Merkle and Meissner corpuscles) responsible for picking up low frequency vibrations around the waist and the propensity for fat to accumulate in this area (as compared to the head, neck and wrist) make the waist a poor location for wearable vibratory devices. Although the neck was found to have acute sensitivity, it might not be an ideal placement for wearable devices with visual display interfaces. Consequently, the selection of the best body placement for wearable devices might override the site of highest vibratory sensitivity for a site that is more accessible and that promotes better user-device interaction. However, adequate frequency and amplitude must be selected for the alerting mechanism.

As previously mentioned, locus 2 of the head (above the left ear) was statistically more sensitive than locus 20 of the waist (right lateral region). This may suggest a better transmission of vibration through bones rather than flesh. But this result is contradicted by the fact that the wrist and the ankle were not as sensitive as the neck, even though they were considered leaner than the neck for the purpose of this experiment. Also, perception of low frequency vibrations, such as those investigated in this study, are far more dependent on stimulation of Merkle and Meissner receptors located near the skin surface than of deeper Ruffini and Pacinian receptors, which have higher frequency periodic tuning ranges (and might well be stimulated by bone-conducted higher frequency vibrations). Although the loci at wrist and ankle areas are not shielded very much by fat, they are not nearly as richly endowed with densely packed Merkle and Meissner receptors as the loci at the neck and head, nor do these loci have very much higher level processing regions in the parietal somatosensory area of the cortex. With low frequency periodic stimulations, near-surface receptor density (and perhaps associated cortical processing resources) is likely to play a much greater role in sensitivity than is bone conduction with higher frequency vibrations, even with momentary instances of high frequency energy with the sharp onsets and offsets of the square wave-driven membrane. In future investigations, to maximally stimulate the Pacinian receptors, participants will be exposed to frequencies closer to $250 \mathrm{~Hz}$ (approximate peak sensitivity for these receptors). However, because Pacinian receptors are located in deep subcutaneous tissue, they may also require higher amplitudes (i.e. battery power) to stimulate.

Although gender has been associated with acuity of the cutaneous sense (Boff et al. 1986), the present study did not find a significant difference in frequency thresholds between males and females. As previously discussed, most females and males follow the gynoid and android body constitutions, respectively. But there was no statistical gender difference in frequency thresholds between loci located in the lower half of the body (where adipose tissue tends to mostly accumulate in gynoid constitutions) and those in the upper half (where adipose tissue tends to mostly develop in android constitutions).

Furthermore, every body locus investigated had an average frequency threshold lower than $1 \mathrm{~Hz}$ at $20 \mathrm{~dB}$, which is several orders of magnitude lower than the thresholds found in the literature (Lundstrom et al. 1992, Harazin et al. 2005, Morioka and Griffin 2005). This discrepancy is partly due to the fact that the present study did not manipulate amplitudes but frequencies. Also, unlike studies by Lundstrom et al. (1992), Harazin et al. (2005) and Morioka and Griffin (2005), the results of the present study represent "absolute" threshold values. The disparity of the results can also be explained by the use of square wave signals, which contain a wide range of harmonically rich signals that can worsen signal 
to noise ratios. An accelerometer was not used to measure the actual acceleration magnitude; the linearity of the Mylar cone speakers used in the experiment was not investigated prior to the experiment. Consequently, more research must be done in order to make valid generalizations of the results.

From a design standpoint, the main limitation of this study lies in the fact that vibration was applied directly to the skin. Although in some situations the alert must not be readily noticeable by others, this does not necessarily mean that the actuators must be hidden from public view. In real-world situations it may be more practical to place a vibratory device over items of clothing of varying thicknesses and materials. A thorough analysis of users' tasks and the equipment they carry will reveal the practicality of placing actuators near the skin. Therefore, further cutaneous analyses may be needed in order to predict absolute thresholds through clothing. Another real-world factor that will need to be examined is related to the fact that the participants were not subjected to any major distractions during the tests. However, users of radiation detectors could be frequently exposed to enemy fire, heat and exhaustion. Therefore, vibratory perception must be investigated under more realistic conditions. Moreover, the issue facing users of neutron detectors is not just detection in noisy environments but also speed and accuracy of localization (of the radiation source), which was not addressed in this study but needs to be investigated in future research.

\section{Conclusions}

The outcome of this research will be used in the process of designing a vibratory neutron detection device for homeland security personnel. The data obtained in this study show that the minimal characteristics of an alerting signal for a vibrotactile instrument are $1 \mathrm{~Hz}$ at $20 \mathrm{~dB}$. However, a frequency of $1 \mathrm{~Hz}$ at $20 \mathrm{~dB}$ does not guarantee that the users will feel the stimulation. Also, the current study revealed that, among the six body sites tested (head, neck, upper arm, wrist, waist and ankle), the waist was one of the least sensitive to vibratory stimulations while the neck had more acute sensitivity. However, issues of comfort and conspicuity might override the choice of lowest frequency detection site. Furthermore, selection of adequate frequency and amplitude for a vibratory device requires a thorough investigation of variation in body fat among the user group. However, gender was not found to play a significant role in vibrotactile acuity.

Although the vibratory alert must be felt by the wearer, the device cannot interfere with his or her ability to perform work-related tasks efficiently. In addition, some users may need devices with physically discreet actuation. It has yet to be shown that the placement of the device around the neck (and other sites) will accomplish this goal. Also, since the effect of clothing was not investigated, body placements other than the neck cannot be ruled out at this stage of the investigation.

\section{Acknowledgments}

The authors express their gratitude to Paul Marxhausen for providing his expertise in the experimental design process. The authors would like to thank the Office of Naval Research and the Nebraska Research Initiative for partial funding of this study. 


\section{References}

Boff, K. R., Kaufman, L., and Thomas, J. P. eds. 1986. Handbook of perception and human performance. New York: Wiley.

Cholewiak, R. W., Collins, A. A., and Brill, J. C., 2001. Spatial factors in vibrotactile pattern perception. In: Eurohaptics Conference. Birmingham, UK, 1-4 July 2001, 1-7. Online (accessed August 15, 2005): http://www.eurohaptics.vision.ee.ethz.ch/2001/cholewiak.pdf

Cohen, L. H. and Lindley, S. B., 1938. Studies in vibratory sensibility. American Journal of Psychology, 51, 44-63.

Craig, J. C. and Sherrick, C. E., 1982. Dynamic tactile displays. In: W. Schiff and E. Foulke, eds. Tactual perception: A sourcebook. Cambridge, UK: Cambridge University Press, 209-233.

Dennerlein, J. T., Millman, P. A., and Howe, R. D., 1997. An industrial application of Vibrotactile feedback. In: Sixth annual symposium on haptic interfaces for virtual environment and teleoperator systems, International Mechanical Engineering Conference and Exhibition of the American Society of Mechanical Engineering, Dallas, TX, November 15-21 1997.

Goff, G. D., et al., 1965. Vibration perception in normal man and medical patients. Journal of Neurology, Neurosurgery and Psychiatry, 28, 503-509.

Goldstein, E. B., 2002. Sensation and perception, 6th ed. Pacific Grove, CA: Wadsworth.

Goodfellow, L. D., 1938. The stability of auditory and vibro-tactile thresholds. The Journal of General Psychology, 18, 49-55.

Harazin, B., et al., 2005. Measurements of vibrotactile perception thresholds at the fingertips in Poland. Industrial Health, 43, 535-541.

International Organization for Standardization, 2003. ISO 13091-2:2003 (E) Mechanical vibration thresholds for the assessment of nerve dysfunction - Part 2: Analysis and interpretation of measurements at the fingertips.

Johnson, E. P. ed. 2000. ACSM's Guidelines for exercise testing and prescription, 6th ed. Lippincott Williams and Wilkins, Philadelphia, PA: Lippincott Williams and Wilkins.

Lundstrom, R., Stromberg, T., and Lundborg, G., 1992. Vibrotactile perception threshold measurements for diagnosis of sensory neuropathy. Description of a reference population. International Archives of Occupational and Environmental Health, 64 (3), 201-207.

Morioka, M. and Griffin, M. J., 2005. Thresholds for the perception of hand-transmitted vibration: Dependence on contact area and contact location. Somatosensory and Motor Research, 22 (4), 281-291.

Plant, G., Gnosspelius, J., and Spens, K. E., 1994. Three studies using the KTH speech tracking procedure. STL-QPSR, 35, 103-134.

Renold, A. E. and Cahill, G. F. Jr., 1965. Section 5: Adipose tissue. In: R. Reiser, ed. Handbook of physiology. Washington, DC: American Physiological Society.

Siegel, S. and Castellan, N. J. Jr., 1988. Nonparametric statistics for the behavioral sciences. Boston, MA: McGraw-Hill.

Siri, W. E., 1956. The gross composition of the body. Advances in Biological and Medical Physics, 4, 239-280.

Stuart, M., et al., 2003. Effects of aging on vibratory detecting thresholds at various body regions. BMC Geriatrics [online], 3 (1); doi: 10.1186/1471-2318-3-1; Online: http://www.biomedcentral. $\underline{\mathrm{com} / 1471-2318 / 3 / 1}$

Verrillo, R. T., 1979. Change in vibrotactile thresholds as a function of age. Sensory Processes, 3, 49-59.

Weber, E. H., 1834. De tactu. New York: Academic (Republished 1978). 